\title{
3D Hydrodynamics and Vertical Mixing in a Stratified Estuary
}

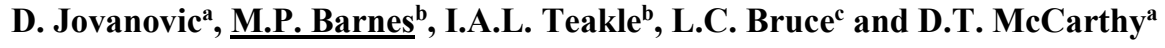 \\ ${ }^{a}$ Environmental and Public Health Microbiology (EPHM) Laboratory, Civil Engineering Department, \\ Monash University, Victoria, Australia \\ ${ }^{b}$ Water and Environment Group, BMT WBM, Brisbane, Australia \\ ${ }^{c}$ School of Earth and Environment, The University of Western Australia, Western Australia, Australia \\ Email: matthew.barnes@bmtwbm.com.au
}

\begin{abstract}
Estuaries are commonly classified by their flow characteristics and the extent of salt and fresh water mixing observed under normal conditions. Highly stratified, "salt-wedge" estuaries are characterised by a well-defined horizontal halocline, with a fresh surface water layer forming above the saline coastal water. Salt-wedge estuaries have large fluvial to tidal flow ratio and typically occur along microtidal coasts where the tidal range is less than $2 \mathrm{~m}$. The mixing of fresh river water and saline coastal water in estuaries is primarily determined by turbulent mixing and to a much lesser extent molecular diffusion (e.g. Masselink and Hughes, 2003). Under low turbulent energy conditions the river and coastal water masses remain segregated. As turbulent mixing increases, such as during a flood event, the estuary may temporarily transition to a "partially" or "well-mixed" condition.

The hydrodynamics and vertical mixing in a stratified estuary has been explored using high-resolution datasets and numerical models. The hydrodynamics and vertical structure in the Yarra River estuary (Melbourne, Australia) was observed using a combination of ADCP (Acoustic Doppler Current Profiler) and EC/T (Electrical Conductivity and Temperature) instruments. The observed features of the estuary and position of the halocline were subsequently simulated using a 3D Non-Linear Shallow Water Equation (NLSWE) solver coupled with turbulent mixing and atmospheric exchange models. The key aspects of the numerical modelling approach required to accurately capture the vertical structure of the Yarra River estuary included:
\end{abstract}

- The inclusion of approximately 200 urban stormwater discharge inputs,

- A hybrid z-coordinate with surface sigma-layer model mesh vertical discretization, and

- Coupling of the 3D hydrodynamic model with a two-equation vertical turbulence scheme.

The coupling of the hydrodynamics with the vertical turbulence scheme was an essential component of the modelling system. Following this approach, the 1D (vertical) transport equations of momentum, salt and heat are calculated and used by NLSWE solver in the 3D circulation calculations. Efficient integration of the 3D NLSWE was achieved through a mode splitting scheme, whereby different components of the governing equations were updated using an appropriate timestep selected by taking into account physical and numerical convergence and stability considerations.

This model will ultimately form the basis for a 3D hydrodynamic-microorganism model through the coupling with the Aquatic EcoDynamics (AED ${ }^{2}$ ) modelling library. It is anticipated that this tool will be used by industry partners (Melbourne Water) to make scientifically-informed management decisions for improvement of water quality in the Yarra River estuary.

Keywords: $\quad$ Salt wedge intrusion, water quality, Yarra River, TUFLOW FV 


\section{THE YARRA RIVER CATCHMENT AND ESTUARY}

\subsection{Study Site}

The Yarra River is a major river in Victoria which flows westward from the southern side of the Great Dividing Range, passing through the heart of the city of Melbourne and discharging into Port Philip Bay at Hobson Bay. Total length of the Yarra River is 242 $\mathrm{km}$ and it drains the catchment of about 4000 $\mathrm{km}^{2}$ (Sokolov and Black, 1996). The catchment can be divided in three distinct sections (Sinclair et al., 1989):

- $\quad$ Lower part of the catchment (ca. 900 $\mathrm{km}^{2}$ ) is primarily urbanized and supports population of over 2 million people,

- About $1800 \mathrm{~km}^{2}$ of the upper catchment is mainly forested and closed to protect the quality of water supply to metropolitan Melbourne, and

- The remainder (ca. $1300 \mathrm{~km}^{2}$ ) is devoted to agriculture.

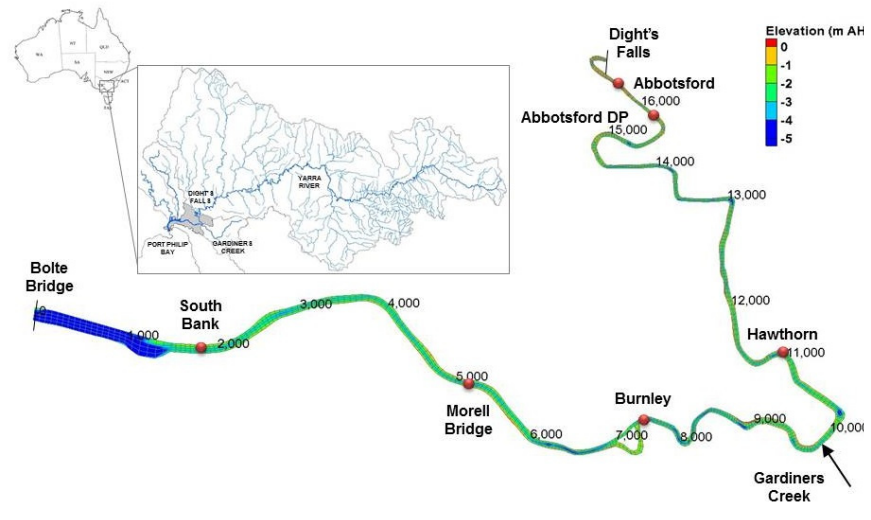

Figure 1. Yarra River catchment and upper estuary section model mesh with monitoring stations (chainage distance shown as metres from Bolte Bridge): water level Abbotsford, Hawthorn, Burnley, South Bank; flow velocity Morell Bridge; electrical conductivity and temperature $(\mathrm{EC} / \mathrm{T})-$ Abbotsford, Morell Bridge; salinity and temperature vertical profiles - Abbotsford DP, Hawthorn, Morell Bridge and South Bank.

The estuarine section of the Yarra River extends $22 \mathrm{~km}$ upstream from Hobson Bay to Dights Falls, an artificial weir which physically divides estuarine and riverine sections. This section can be further divided into two parts: an upper estuary section with depth from $<1 \mathrm{~m}$ to $5 \mathrm{~m}$, and a lower estuary section downstream from South Bank which has been heavily modified over the years and dredged to depths of $8-13 \mathrm{~m}$ to accommodate the needs of the Port of Melbourne (Ellaway et al., 1982, Beckett et al., 1982). The estuary section considered in the present study and key locations referred to throughout the paper are shown in Figure 1.

Approximately $70 \%$ of the average annual fluvial flow rate at the mouth of the Yarra River $\left(\sim 20 \mathrm{~m}^{3} / \mathrm{s}\right)$ is attributed to flows over Dights Falls (Sokolov and Black, 1996). The flow pattern of the Yarra River is very much seasonal, with lower flows recorded over summer and autumn months and higher flows over winter and spring (Beckett et al., 1982). The other 30\% of fresh water inputs to the estuary include: Gardiners Creek in the upper section of the estuary, about $7.6 \mathrm{~km}$ downstream of Dights Falls (Figure 1), the Maribyronong River and Moonee Ponds Creek in the lower part of the estuary, about 3 and $5 \mathrm{~km}$ upstream of the mouth, and over 200 stormwater drains that discharge directly into the estuary.

\subsection{Field Monitoring and Data Collection}

Continuous high resolution water level monitoring is conducted by Melbourne Water at four monitoring stations within the estuary, namely: Abbotsford, Hawthorn, Burnley and South Bank. Velocity monitoring was conducted at the Morell Bridge monitoring station using two Acoustic Doppler Current Profiler (ADCP) devices. One device was placed in a shallower part of the cross section while the other was positioned at the deepest point of the cross section. The devices were measuring all three components of the velocity vector at minute intervals in fixed $1 \mathrm{~m}$ cells (bins) vertically through the water column as well as in a surface dynamic cell (that adapted to the varying water level). The ADCPs were deployed from October 2012 to September 2014 and regularly serviced throughout this period.

Continuous monitoring of electrical conductivity (EC) and temperature (T) was conducted at Abbotsford and Morell Bridge monitoring stations. Abbotsford monitoring station is located at the upstream end of the estuarine section of the Yarra River, just below the Dights Falls, and it is largely free of the salt-wedge impacts while still being under tidal influences. This site was equipped with a single EC/T sensor located approximately $20 \mathrm{~cm}$ below the water level which is assumed to be representative of the entire water column. Conversely, Morell Bridge monitoring site is under significant impacts of both tides and salt-wedge and this site was equipped with two EC/T sensors. One was located approximately $20 \mathrm{~cm}$ below the water surface measuring the conductivity and temperature of the top freshwater layer, while the other was attached to the ADCP device and was measuring conductivity and temperature of the bottom layer, i.e. salt-wedge. Measurements were available at 6minutely intervals. EC and T measurements were used to calculate salinity following Electrical Conductivity method (Eaton et al., 2005). 
To obtain salinity and temperature distributions vertically through the water column, depth profiling monitoring campaigns were conducted. Four monitoring sites along the estuary that exhibit different extent of the saltwedge intrusion were chosen: Abbotsford, Hawthorn, Morell Bridge and South Bank. At each site multiparameter probe was used to measure salinity and temperature along the depth at $30-50 \mathrm{~cm}$ intervals depending on the position of the halocline/thermocline. In total 84 depth profiles of salinity and temperature were obtained over the 10 monitoring campaigns encompassing a variety of hydrological and climatic conditions. Only a selection of depth profiles obtained on 30 April 2013 is presented in this paper. The authors may be contacted for further information.

\section{MODELLING THE YARRA ESTUARY PHYSICAL PROCESSES}

\subsection{Numerical Modelling System Overview}

The hydrodynamic modelling presented in this study builds on the previous work by Bruce et al. (2014) using TUFLOW FV. Key aspects of the work presented here include:

- An increased horizontal and vertical resolution of the numerical model,

- Model verification using data obtained during a significant Yarra River flow event, and

- Model verification to measurements of the salinity and temperature vertical structure.

For the present study, the Yarra River estuary was resolved using an unstructured mesh comprised of predominantly quadrilateral elements. In the horizontal dimension, the model consists of 1,644 surface mesh cells with resolution varying from approximately 20-50 m. Four elements were typically used to define the Yarra estuary/river cross-section. In the vertical dimension, a hybrid z-coordinate grid configuration with eight surface "sigma" layers was adopted. The z-coordinate layers were applied at a $0.2 \mathrm{~m}$ resolution between an elevation of $-1 \mathrm{~m} \mathrm{AHD}$ and the estuary/river bed (with a variable bottom layer thickness). The eight sigma layers were applied between $-1 \mathrm{~m}$ AHD and the water surface. The multiple surface sigma layers allows for a high resolution of the water surface boundary layer while tracking tidal water surface variations.

The model bathymetry was derived using three hydrographic surveys conducted in 2004, 2009 and 2012 , supplied by Parks Victoria, Melbourne Water and Red Mapping. The first and the last survey were conducted using a vessel logging depth and position, while second survey measured 160 cross sections within the estuary. All data was used and interpolated to obtain cell elevations.

At the upstream model boundary, the freshwater flow rates were obtained from Melbourne Water gauging stations on the Yarra River at Fairfield and on Merri Creek at Northcote while electrical conductivity (used to obtain salinity) and temperature were measured locally at Dights Falls. Similar was done to describe Gardiners Creek input, where measured flow rate was obtained from Melbourne Water, while EC/T was continually measured at the station $1 \mathrm{~km}$ upstream of the confluence with the Yarra River. The discharges from 208 storm water drains were also included and this boundary condition information was derived using MOPUS rainfall run off model (McCarthy et al., 2011). Details on production of stormwater inputs can be found in Jovanovic et al. (2015). A tidally varying water level recorded at South Bank station was applied as downstream boundary condition. Salinity and temperature data for the Hobson bay was obtained from the Port of Melbourne Corporation. Although this data was recorded some distance downstream of the model boundary, depth profile measurement campaigns revealed that most of the cross section at South Bank was comprised of sea water (data not shown). Therefore, the measured data has been applied across the whole cross section.

The meteorological data was supplied by the Bureau of Meteorology and consisted of precipitation, air temperature, relative humidity and wind speed and direction. All data was acquired from the Melbourne Regional Office station, which is located within the estuary catchment except wind speed and direction measurements which were conducted at Essendon Airport, $\sim 10 \mathrm{~km}$ away.

Salinity and temperature were simulated within the model as density-coupled scalar constituents in order to incorporate baroclinic density gradient forcing and the effect of vertical density stratification on the water column turbulent mixing. The General Ocean Turbulence Model (GOTM - Umlauf et al. 2003) was coupled with the hydrodynamic model through the external turbulence Application Programming Interface (API). Vertical mixing and the sensitivity to alternative models are discussed further in Section 2.3 and Section 2.4.

A bottom roughness length scale of $1 \mathrm{~mm}$ for a single generic bed surface was represented throughout the model domain. This was assumed to be a suitable representation of the bed throughout the lower Yarra River which is nominally dominated by $70 \%$ silt and $30 \%$ fine to medium sands (Parks Victoria, 2007). Within TUFLOW FV horizontal and vertical reconstructions are performed separately. For the present study a first-order horizontal 
reconstruction (Leveque, 2002) was combined with a second-order vertical reconstruction (Fringer et al., 2005). Most other model configurations and parameters adopted the "default" settings (refer BMT WBM, 2014).

\subsection{Hydrodynamics}

The 3D hydrodynamic model predictive skill was tested statistically with calculations of the Index of Agreement (IOA) and the Mean Absolute Error (MAE). The IOA was originally developed by Willmott (1981) and subsequently modified in Willmott et al. (1985):

$$
I O A=1-\frac{\sum_{i=1}^{N}|O-P|^{2}}{\sum_{i=1}^{N}(|P-\bar{o}|+|O-\bar{o}|)^{2}} \quad \text { Equation } 1
$$

Where $O$ is the observed data and $P$ is the model predictions over a given time period divided into $N$ increments. The overbar denotes the time averaged mean of the given variable.

Following Willmott (1981) and Willmott et al. (1985), the IOA can vary from 0 to 1 with higher values indicating better model predictive skill. While there are no generic guidelines for the interpretation of the IOA, a value meaningfully larger 0.5 is generally considered to indicate satisfactory model performance (Willmott et al. 1985).

The $M A E$ was adopted to quantify the model error in dimensional units and, as suggested by its name, provides a measure of model performance on an average sense. The $M A E$ is computed as follows:

$$
M A E=N^{-1} \sum_{i=1}^{N}|O-P| \quad \text { Equation } 2
$$

The two-month hindcast period included a high flow event with a peak discharge close to $200 \mathrm{~m}^{3} / \mathrm{s}$ at Dights Falls on 01 June 2013 (as gauged by Melbourne Water). The model skill is particularly high with regard to water level $(\mathrm{IOA}>0.95)$ and the downstream component of the current velocity (IOA $>0.80$ ). The MAE up to $0.05 \mathrm{~m}$ for water level and $0.12 \mathrm{~m} / \mathrm{s}$ for currents at the locations tested is due to a minor phase discrepancy between the observed and predicted variables rather than a significant difference in magnitude.

A time series comparison of the observed and predicted water level at Burnley and Hawthorn for a two-week subset of the model verification period is shown in Figure 2. The tidal anomaly recorded at Burnely $(\sim 1 \mathrm{~m})$ and Hawthorn $(\sim 2 \mathrm{~m})$ during the high flow event is accurately predicted by the hindcast simulation. The more typical periods of relatively low river base flow and tidally dominated water level variation are also represented accurately.
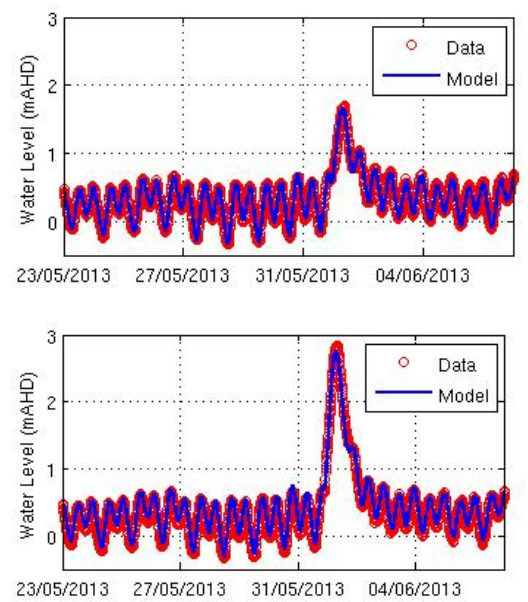

Figure 2. Comparison of Observed and Modelled Time Series of Water Level at Burnley (top) and Hawthorn (bottom).

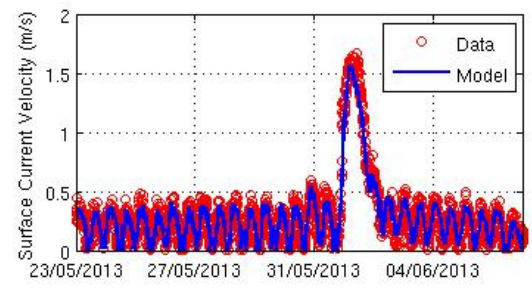

Figure 3 compares the observed and predicted surface and near current velocity at Morell Bridge for the shallow ADCP deployment. Similar to the water levels in the lower estuary, the current velocity is typically dominated by the semidiurnal tide and is predicted accurately by the $3 \mathrm{D}$ model. During these periods, the peak surface currents are up to $0.5 \mathrm{~m} / \mathrm{s}$ and align in the downstream direction (approximately $280 \mathrm{degN}$ at Morell Bridge). The current behavior differs significantly in the near bed layer where the peak velocities

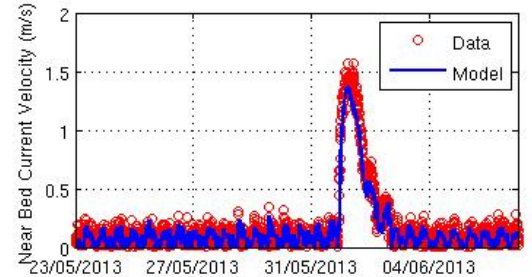

Figure 3. Comparison of Observed and Modelled Time Series of Current Velocity at Morell Bridge: Surface $1 \mathrm{~m}$ (top) and Bottom 1m (bottom) seldom exceed $0.2 \mathrm{~m} / \mathrm{s}$ and align in the upstream direction (approximately $100 \mathrm{deg} \mathrm{N}$ at Morell Bridge). This represents the dense, salt-wedge intrusion driven by the tidal forcing at the river mouth.

During the high flow event the stratification at Morell Bridge temporally breaks down and the surface and near bed currents align in the downstream direction.

Figure 3 shows good consistency between the model and observations in terms of timing and magnitude of currents during the high flow event. 


\subsection{Vertical Mixing}

Validation of the instantaneous vertical structure predicted by the $3 \mathrm{D}$ model is shown in Figure 4 for salinity and temperature at Morell Bridge and Hawthorn. The observations and model results are in close agreement and show the fresh, slightly cooler surface layer and the underlying saline layer. The tapering of the salt-wedge thickness between Morell Bridge and further upstream at Hawthorn is evident in the data and hindcast predictions. The position of halocline was at a depth of 0.5-1.0 $\mathrm{m}$ at Morell Bridge and 1.5-2.0 $\mathrm{m}$ at Hawthorn.

The predicted instantaneous longitudinal salinity structure is presented in Figure 5 and shows the fresh surface layer extending to the downstream model boundary at the Bolte Bridge (chainage $0 \mathrm{~m}$ ) and the tip of the salt-wedge located approximately $1 \mathrm{~km}$ downstream from Abbotsford. It is noted that the salt-wedge intrusion was not detected at Abbotsford during the monitoring campaign. The skill of the salinity prediction was also tested statistically using continuous the EC time series data and yielded the following results at Morell Bridge:

- Surface salinity IOA/MAE: $0.90 / 1.01 \mathrm{psu}$

- Near bed salinity IOA/MAE: 0.60 / 9.78 psu

It is noted that considerable scatter existed in the near bed EC dataset and that this instrument required regular servicing throughout the monitoring campaign. Furthermore, the values recorded were often inconsistent with the depth profiles obtained at at this lcoation (refer Figure 4). Consequently, there is some concern regarding the reliability of this dataset and the IOA and MAE values obtained at Morell Bridge.

\subsection{Model Sensitivity}
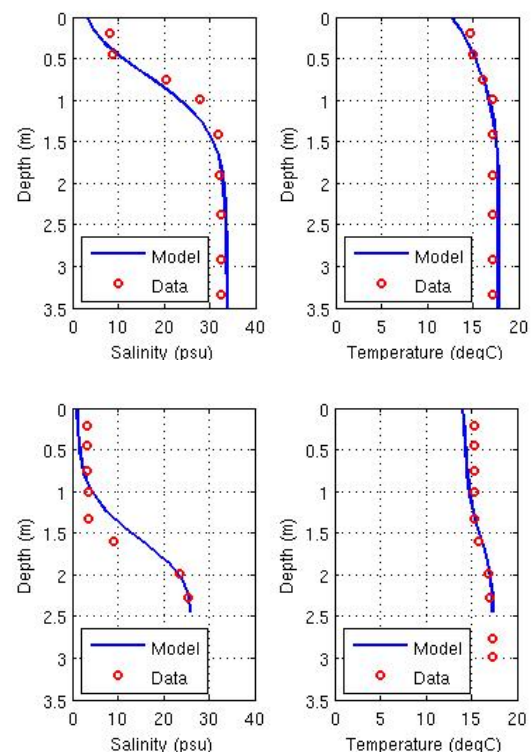

Figure 4. Comparison of Observed and Modelled Salinity and

Temperature Profiles at Morell

Bridge 30/04/2013 08:15 (top) and Hawthorn 30/04/2013 14:55 (bottom)

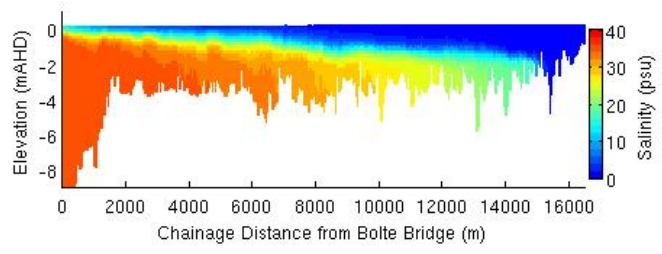

Figure 5. Modelled longitudinal salinity distribution 30/04/2013 08:15

The development and sensitivity testing of the Yarra estuary model indicated that the adopted vertical discretisation and turbulent mixing model significantly influenced the predicted stratification.

Figure 6 compares the instantaneous current velocity, salinity and temperature profiles at Morell Bridge and Hawthorn for three alternative vertical disretisations (corresponding data at Morell Bridge is shown in Figure 4):
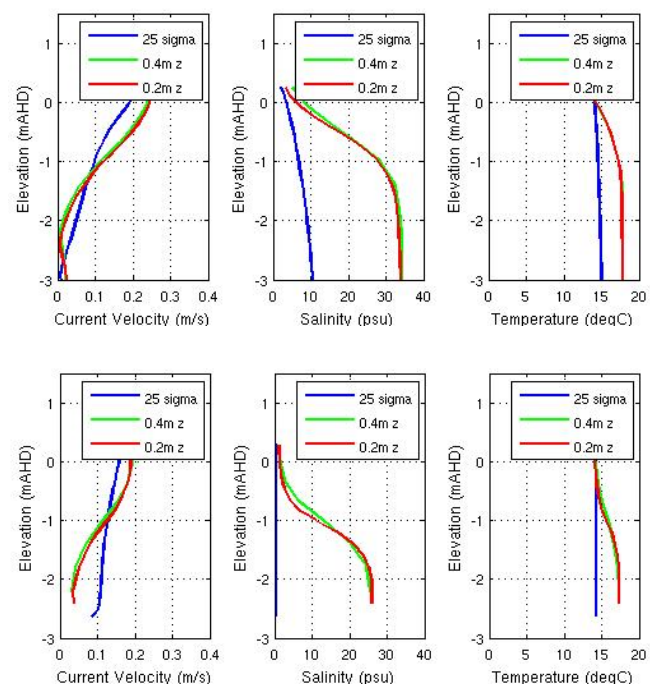

Figure 6. Model Sensitivity to Vertical Discretisation at Morell Bridge (top) and Hawthorn (bottom) 30/04/2013 08:15
- 25 sigma-layers from the estuary bed to water surface,

- $\quad$ hybrid $\mathrm{z}$-coordinate grid with $0.4 \mathrm{~m}$ resolution layers between $-1 \mathrm{~m}$ AHD and the estuary bed and eight sigma layers applied between $-1 \mathrm{~m}$ AHD and the water surface, and

- $\quad$ hybrid z-coordinate grid with $0.2 \mathrm{~m}$ resolution layers between $-1 \mathrm{~m}$ AHD and the estuary bed and eight sigma layers applied between $-1 \mathrm{~m}$ AHD and the water surface (adopted configuration).

The hybrid z-coordinate approach is shown to be particularly suited to the highly stratified environment. The difference between the $0.4 \mathrm{~m}$ and $0.2 \mathrm{~m}$ resolution approaches is relatively minor, with the latter ultimately adopted due to the prediction of slightly steeper gradients and the associated small improvement to the predictive skill of the model when tested against the observed salinity and temperature profile datasets (including the data shown in Figure 4).

Figure 6 suggests that a sigma-layer only discretization over predicts the vertical mixing, leading to a breakdown in stratification at Hawthorn and therefore a grossly inaccurate prediction of salt-wedge intrusion. It is hypothesized that the 
stretched terrain following coordinates generate additional spurious numerical mixing in comparison to the fixed z-layer approach. It is noted that model adjustments adopting a second order spatial scheme (horizontal) or reducing horizontal mixing would potentially limit the sigma-layer case numerical mixing, but these potential sensitivities were not explored further in the present study.

The model sensitivity to the vertical turbulent closure scheme was also tested, including:

- A parametric mixing model (BMT WBM, 2013) that assumes a parabolic eddy-viscosity/scalar-diffusivity distribution and includes a simple Munk and Anderson (1948) stability function,

- GOTM 2-equation k-omega model, e.g. Burchard and Baumert (1995) (with default parameters), and

- $\quad$ GOTM 2-equation k-epsilon model, e.g. Umlauf et al. (2003) (with default parameters).

Despite testing numerous configurations the simple parametric model was not able to represent the highly stratified circulation dynamics. The GOTM 2-equation models tested here were better suited to simulating the Yarra River estuary salt wedge environment and predicted virtually identical vertical structures. This suggests that either the k-omega or k-epsilon models are well suited to simulating vertical mixing in the lower Yarra River. It is noted that the results presented in Section 2.2 and Section 2.3 of this paper adopted the GOTM komega model.

\section{DISCUSSION AND CONCLUSIONS}

The value of a verified 3D hydrodynamic model for simulating the fate of water-borne constituents in the Yarra River estuary is demonstrated in Figure 7 which illustrates the predicted advection-dispersion of a plume, represented by a conservative tracer entered to the model between Morell Bridge and Burnley, during an ebb flow condition (the instantaneous salinity distribution for this time was previously shown in Figure 5). The following scenarios are considered:

- 2D-depth average hydrodynamics and plume release,

- 3D hydrodynamics with buoyant plume surface release (representative of a storm water drain/emergency relief structure (ERS) discharge), and

- 3D hydrodynamics with dense plume near-bed release (representative of a dredge-related sediment plume)

The 2D scenario assumes a depth average vertical structure. Regardless of the plume characteristics (e.g. buoyant or dense) the concentration is diluted evenly throughout the water column and is transported in the direction of the depth averaged estuarine flow. The consequence of this simplification is highlighted in the 3D scenarios shown in Figure 7. For the
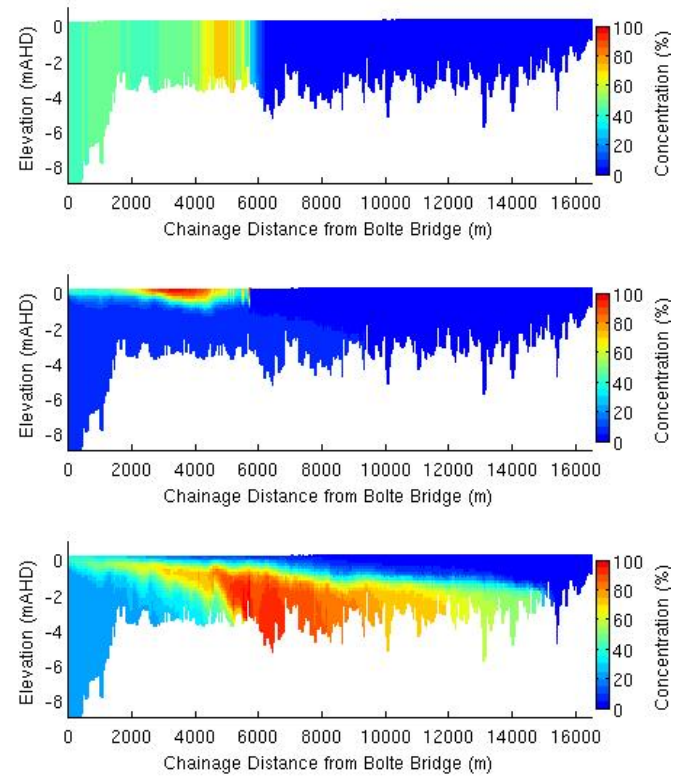

Figure 7. Modelled longitudinal tracer distribution ebbing flow: 2D-depth average plume release (top); 3D buoyant plume surface release (centre) and 3D dense plume bed release (bottom) buoyant plume case, the $3 \mathrm{D}$ result clearly demonstrates that the high concentration surface accumulation is under predicted by the 2D model (by up to a factor 2). Potentially of greater significance is the difference between the $2 \mathrm{D}$ and $3 \mathrm{D}$ results for the dense plume scenario. Here it is shown that the $2 \mathrm{D}$ model is not an appropriate tool for predicting the accumulation of a dense plume in a stratified estuary. In contrast, the $3 \mathrm{D}$ model shows the dense plume accumulation remaining within the saltwedge layer and extending approximately $10 \mathrm{~km}$ upstream from the location of origin.

The TUFLOW FV Yarra River estuary model will ultimately form the basis for a 3D hydrodynamicmicroorganism model through the coupling with the Aquatic EcoDynamics (AED ${ }^{2}$ ) modelling library (e.g. Hipsey et al., 2013; Bruce et al., 2014). Survival of the faecal microorganisms/pathogens are known to be impacted by number of environmental factors such as: temperature, salinity, sunlight, $\mathrm{pH}$ and dissolved oxygen (Crane and Moore, 1985). Furthermore, it is well established that sediments, both suspended in the water column and at the estuary bed, can provide certain extent of protection from detrimental environmental effects and prolong survival of pathogens (Pachepsky and Shelton, 2011). Therefore, ability to resolve the stratified circulation dynamics, including accurate distribution of the environmental variables (i.e. salinity, temperature, total suspended solids etc.) is an essential step in describing the microbial dynamics within the Yarra River.

In addition, the demonstrated ability to simulate buoyant plume release without extensive mixing within the saltwedge is extremely important considering presence of 218 stormwater drains that discharge directly into the 
estuary. During discharge events, the stormwater plume typically occupies the top of the water column where the exposure to recreational activities is the highest (therefore increasing the public health risk). A previous study, which employed a simple conceptual modelling approach, showed that on average the stormwater contribution of the total load of Escherichia Coli (E. coli, a common faecal indicator microorganism) to the estuary during wet weather remained marginal ( 10\%) (Jovanovic et al., 2015), but was significant in some cases (around $50 \%$ of the total load). Due to the modelling limitations (e.g. box model for the estuary), this study was only able to generally assess the impact of stormwater on E. coli dynamics. Future research using TUFLOW FV as hydrodynamic driver will test previous findings, as well as explore stormwater impacts on much more refined temporal and spatial scale. Furthermore, the 3D hydrodynamic-microorganism model will be used to gain an improved understanding of faecal microorganism/pathogens dynamics and to scientificallyinform management decisions to improve the health of the Yarra River estuary.

\section{ACKNOWLEDGMENTS}

The authors wish to acknowledge Melbourne Water and Australian Research Council for providing funding for this project; M. Hipsey from the University of Western Australian for helping to establish the modelling framework; and C. Shang, P. Kolotelo, and R. Williamson for their help with the field experiments.

\section{REFERENCES}

Beckett, R., Easton, A., Hart, B. and McKelvie, I. (1982). Water movement and salinty in the Yarra and Maribyrnong estuaries. Marine and Freshwater Research, 33, 401-415.

BMT WBM (2013). TUFLOW FV Science Manual, available at: http://www.tuflow.com/ProductDownload.aspx?tuffv, 2013.

BMT WBM (2014). TUFLOW FV User Manual, available at: http://www.tuflow.com/Download/TUFLOW_FV/Manual/FV-UserManual-2014.01.pdf, 2014.

Bruce, L. C., Cook, P. L. M., Teakle, I. and Hispsey, M. R. (2014). Hydrodynamic controls on oxygen dynamics in a riverine salt wedge estuary, the Yarra River estuary, Australia. Hydrol. Earth Syst. Sci., 18, 13971411.

Burchard, H., and Baumert, H. (1995). On the performace of a mixed-layer model based on the $\kappa-\varepsilon$ turbulence closure. J. Geophys. Res., (C5), 100, 8523-8540.

Crane, S. R. and Moore, J. A. (1985). Modeling enteric bacterial die-off: A review. An International Journal of Environmental Pollution, 27, 411-439.

Eaton, A., Franson, M. A. H., Association, A. P. H. and Federation, W. E. (2005). Standard methods for the examination of water \& wastewater, Washington, D.C., American Public Health Association.

Ellaway, M., Hart, B. T. \& Beckett, R. (1982). Trace metals in sediments from the Yarra river. Marine and Freshwater Research, 33, 761-778.

Fringer, O.B., Armfield, S. W. and Street, R. L. (2005). Reducing numerical diffusion in interfacial gravity wave simulations. International Journal for Numerical Methods in Fluids: 49, 301-329.

Hipesy, M.R., Bruce, L.C. and Kilminster, K. (2013). A 3D hydrodynamic-biogeochemical model for assessing artificial oxygenation in a riverine salt-wedge estuary. MODSIM2013 - 20th International Congress on Modelling and Simulation. Modelling and Simulation Society of Australia and New Zealand, December 2013, Adelaide, Australia.

Jovanovic, D., Henry, R., Colemam, R., Deletic, A. and McCarthy, D. (2015). Integrated conceptual modelling of faecal contamination in an urban estuary catchment. Water Science and Technology, in press.

Leveque, R.J. (2002). Finite Volume Methods for Hyperbolic Problems, Cambridge University Press.

Masselink, G. and Hughes, M. G. (2003). Introduction to Coastal Processes \& Geomorphology, Hodder Arnold, London.

McCarthy, D. T., Deletic, A., Mitchell, V. G. and Diaper, C. (2011). Development and testing of a model for Micro-Organism Prediction in Urban Stormwater (MOPUS). Journal of Hydrology, 409, 236-247.

Pachepsky, Y. A. and Shelton, D. R. (2011). Escherichia coli and fecal coliforms in freshwater and estuarine sediments. Critical Reviews in Environmental Science and Technology, 41, 1067-1110.

Parks Victoria (2007). Long term sustainable dredging strategy for Maribyrnong and Yarra Rivers, 2007.

Sinclair, P., Beckett, R. and Hart, B. T. (1989). Trace elements in suspended particulate matter from the Yarra River, Australia. Hydrobiologia, 176-177, 239-251.

Sokolov, S. and Black, K. P. (1996). Modelling the time evolution of water-quality parameters in a river: Yarra River, Australia. Journal of Hydrology, 178, 311-335.

Umlauf, L., Burchard, H. and Hutter, K. (2003). Extending the $\kappa-\omega$ turbulence model towards oceanic applications. Ocean Modelling, 5, 195-218.

Umlauf, L. and Burchard, H. (2013). A generic length-scale equation for geophysical turbulence models, Journal of Marine Research, 61, 235-265. 